\title{
Biography_Judith Clements
}

(C) Springer Science+Business Media, LLC, part of Springer Nature 2019

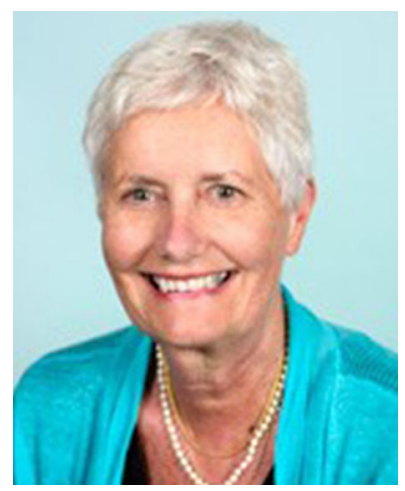

Dr. Judith Clements

Judith Clements obtained her PhD from Monash University, Melbourne, Australia, in 1989. She moved to Queensland University of Technology (QUT) in Brisbane, Australia, in 1996 where she initiated and led the Cancer Program within the School of Biomedical Sciences and Institute of Health and Biomedical Innovation (IHBI) from 1997 to 2014. During that time, the program grew from a small group of 6-8 researchers to now $>100$ staff and postgraduate students. She was cofounder and former Scientific Director, until 2017, of the Australian Prostate Cancer Research Centre-Queensland, within IHBI, QUT and which is located at the Translational Research Institute, Brisbane. She was continuously funded as a federal government funded National Health \& Medical Research Council (NHMRC) Principal Research Fellow for 16 years from 2000 to 2016 and was actively involved in NHMRC peer review in that time. She was awarded the Queensland Women in Technology Biotech Outstanding Achievement Award for 2012, and the prestigious title of Distinguished Professor, the first woman in QUT's history, in 2013 and Emeritus Professor in 2018. She became a fellow of the Australian Academy of Health \& Medical Sciences in 2017.

The focus of her research is the role of the prostate-specific antigen (PSA) (the current test for prostate cancer)-related kallikrein peptidases in the tumour microenvironment and their utility as biomarkers or therapeutic targets for prostate and ovarian cancer. In recognition of her contribution to the kallikrein field internationally, she was awarded the prestigious EK Frey Werle Silver \& Gold Medals, in 2000 and 2007 , respectively. She has over 265 publications (> 14,000 citations; $\mathrm{H}$ index 62) in scientific journals and collaborates widely with colleagues in the US, Canada, the UK and Europe. She co-founded, and directed until 2017, the national prostate cancer tissue bank - the Australian Prostate Cancer BioResource - which is a key resource ( $>6700$ men recruited to date) that underpins prostate cancer research nationally. She was also co-leader of the Queensland node of the international genome wide association study consortium for prostate cancer, PRACTICAL, that has discovered $>160$ new genetic regions that are associated with prostate cancer risk.

Publisher's note Springer Nature remains neutral with regard to jurisdictional claims in published maps and institutional affiliations. 